\title{
Profound influence of different methods for determination of the ankle brachial index on the prevalence estimate of peripheral
} arterial disease

\author{
Stefan F Lange*1,9, Hans-Joachim Trampisch ${ }^{1}$, David Pittrow ${ }^{2}$, \\ Harald Darius ${ }^{3}$, Matthias Mahn ${ }^{4}$, Jens R Allenberg5, Gerhart Tepohl6, \\ Roman L Haberl7, Curt Diehm ${ }^{8}$ for the getABI Study Group
}

\begin{abstract}
Address: ${ }^{1}$ Department of Medical Informatics, Biometry and Epidemiology, University of Bochum, Universitätsstr., $150 \mathrm{D}-44801$ Bochum, Germany, ${ }^{2}$ Department of Clinical Pharmacology, Medical Faculty, Technical University of Dresden, Dresden, Germany, ${ }^{3}$ Department of Medicine I, Vivantes Berlin-Neukölln Medical Centre, Berlin, Germany, ${ }^{4}$ Medical Department, Sanofi-Aventis, Geneva, Switzerland, ${ }^{5}$ Department of Vascular Surgery, Ruprecht-Karls University, Heidelberg, Germany, ${ }^{6}$ Internist/Vascular Medicine, Munich, Germany, ${ }^{7}$ Department of Neurology, Municipal Hospital Munich-Harlaching, Germany, ${ }^{8}$ Department of Internal Medicine/Vascular Medicine, Klinikum Karlsbad-Langensteinbach, Affiliated Teaching Hospital of the Ruprecht-Karls University of Heidelberg, Germany and ${ }^{9}$ Institut für Qualitätssicherung und Wirtschaftlichkeit im Gesundheitswesen (IQWiG), Köln, Germany

Email: Stefan F Lange* - stefan.lange@iqwig.de; Hans-Joachim Trampisch - Allenberg@med.uni-heidelberg.de;

David Pittrow - david.pittrow@mailbox.tu-dresden.de; Harald Darius - harald.darius@vivantes.de; Matthias Mahn - Matthias.Mahn@sanofiaventis.com; Jens R Allenberg - Allenberg@med.uni-heidelberg.de; Gerhart Tepohl - ge.tepohl@t-online.de;

Roman L Haberl - r.haberl@khmh.de; Curt Diehm - curt.diehm@kkl.srh.de; the getABI Study Group - david.pittrow@mailbox.tu-dresden.de

* Corresponding author
\end{abstract}

Published: 6 July 2007

BMC Public Health 2007, 7:147 doi:I0.1 186/147/-2458-7-147
Received: 25 September 2006

Accepted: 6 July 2007

This article is available from: http://www.biomedcentral.com/I47I-2458/7//47

(C) 2007 Lange et al; licensee BioMed Central Ltd.

This is an Open Access article distributed under the terms of the Creative Commons Attribution License (http://creativecommons.org/licenses/by/2.0), which permits unrestricted use, distribution, and reproduction in any medium, provided the original work is properly cited.

\begin{abstract}
Background: The ankle brachial index (ABI) is an efficient tool for objectively documenting the presence of lower extremity peripheral arterial disease (PAD). However, different methods exist for $A B I$ calculation, which might result in varying PAD prevalence estimates. To address this question, we compared five different methods of $A B I$ calculation using Doppler ultrasound in 6,880 consecutive, unselected primary care patients $\geq 65$ years in the observational getABI study.

Methods: In all calculations, the average systolic pressure of the right and left brachial artery was used as the denominator (however, in case of discrepancies of $\geq 10 \mathrm{mmHg}$, the higher reading was used). As nominators, the following pressures were used: the highest arterial ankle pressure of each leg (method \#I), the lowest pressure (\#2), only the systolic pressure of the tibial posterior artery (\#3), only the systolic pressure of the tibial anterior artery (\#4), and the systolic pressure of the tibial posterior artery after exercise (\#5). An $A B I<0.9$ was regarded as evidence of PAD.

Results: The estimated prevalence of PAD was lowest using method \#I (18.0\%) and highest using method \#2 (34.5\%), while the differences in methods \#3-\#5 were less pronounced. Method \#I resulted in the most accurate estimation of PAD prevalence in the general population. Using the different approaches, the odds ratio for the association of PAD and cardiovascular (CV) events varied between 1.7 and 2.2.

Conclusion: The data demonstrate that different methods for $A B I$ determination clearly affect the estimation of PAD prevalence, but not substantially the strength of the associations between PAD and CV events. Nonetheless, to achieve improved comparability among different studies, one mode of calculation should be universally applied, preferentially method \#I.
\end{abstract}




\section{Background}

The prevalence of peripheral arterial disease (PAD) is rising since life expectancy is steadily increasing. Intermittent claudication (IC) as a classical manifestation of PAD becomes evident in only a fraction of the affected patients, thus demonstrating that the course is predominantly asymptomatic [1,2]. The clinical importance of the early identification of PAD as a manifestation of generalised atherothrombotic disease has been increasingly acknowledged in the recent years: although limb loss is a rare event in patients with intermittent claudication [3], the presence of PAD is a powerful predictor of future cardiovascular and cerebrovascular events and of increased mortality [4-7]. In primary health care, history taking and physical examination are still the major tools for the diagnosis of PAD, which leads to substantial under-diagnosis of the disease $[8,9]$. Further, the positive predictive value of intermittent claudication or diminished peripheral pulses seems not be sufficiently high $[10,11]$.

The ankle brachial index (ABI) offers a simple and effective method of objectively documenting the functional state of the circulation in the lower limb and thus for the diagnosis of lower extremity PAD. The measurement of $\mathrm{ABI}$ can be performed in general practice using inexpensive equipment and is an efficient tool which improves the quality and efficiency of primary care with regard to PAD $[12,13]$. A normal ABI, indicating good blood flow to the extremity, is around 1.1 [14]. However, in a patient with compromised perfusion of the lower limb, the index is much lower than this. In this case, an ABI below 0.9 is routinely found, and an index below 0.4 indicates severe ischaemic symptoms [15]. Compared to angiography, an ABI less than 0.9 is $90 \%$ sensitive and $98 \%$ specific for a stenosis of $50 \%$ or more in leg arteries $[13,16]$ and, among well-trained operators, the test-retest reliability is excellent $[12,17]$.

Assessment of $\mathrm{ABI}$ is performed by dividing the ankle systolic pressure by the highest brachial systolic pressure [15]. While this procedure allows various possibilities for calculating the ABI, only one mode of calculation is recommended by experts [18]. It appears predictable that different modes of ABI calculation result in different PAD prevalence estimates. Up to now, however, how the different modes of ABI calculation affect the PAD prevalence estimates and the association of PAD with other concurrent manifestations of atherothrombotic disease have not been systematically investigated.

\section{Methods \\ Ethics}

The protocol of the German Epidemiological Trial on Ankle Brachial Index (getABI) was approved by the Ethics Committee of the University of Heidelberg in 2001. All participating patients gave written informed consent. The study was conducted according to the 'Good Epidemiological Practice' recommendations issued by the 'German Working Group Epidemiology' [19].

\section{Study design}

The (getABI) study is a large-scale epidemiological study with a cross-sectional and longitudinal part. Results reported in this paper refer to the cross-sectional part only. The methods and design of the study have been described elsewhere in greater detail $[20,21]$. Briefly, the central study co-ordinating centre selected 34 vascular physicians on the basis of their expertise in PAD. These vascular physicians, serving as centres of excellence, were evenly distributed geographically nation-wide, and each suggested on average 10 general practitioners to the central co-ordinating centre. Appropriate statistical methods were used to check that the distribution of the 344 GPs was representative in terms of location (post codes) and education (internists serving as GPs, and general physicians) for the total number of approximately 56,000 primary care physicians in Germany. Several weeks before the start of the study, in 34 regional meetings the centres of excellence instructed the GPs and their support staff about the requirements of the study and trained them in the clinical measurements, focusing particularly on $\mathrm{ABI}$ assessment.

\section{Patients}

A prevalence assessment of primary care attendees, irrespective of their reason for seeing the doctor, was conducted within a pre-specified week in October 2001. In each practice, the gender and age category of all patients attending the practice and seeing the doctor were recorded in a log-file for each day of the week. The only exclusion criterion was life expectancy $<6$ months. A total of 20 (in exceptional cases up to 25) eligible patients fulfilling the inclusion criteria (age $\geq 65$ years, patient being legally competent and able to co-operate appropriately and providing written informed consent) were recruited, preferably as evenly as possible over this week in order to avoid selection bias. The data management centre was notified by fax about the inclusion of the patients on a daily basis. The baseline visit with the initial study examinations as specified below was to be performed within 6 weeks after the recruitment week. Further investigations included patient and medication history, physical examination and central laboratory tests at entry. The medical history as assessed at baseline included the following conditions: cardiovascular diseases (i.e. myocardial infarction, angina pectoris, revascularisation procedures), cerebrovascular diseases (i.e. stroke, transitory ischaemic attacks, or revascularisation procedures on the carotids), peripheral PAD (i.e. a history with regard to gangrene or amputation [minor and major form] of the lower extremities on account of PAD, IC [pain in the calf muscles while walk- 
ing or during other exertion, which disappears within 10 min at rest], or revascularisation procedures on the peripheral arteries). In addition, the patients completed the WHO Rose questionnaire on intermittent claudication [22].

\section{Determination of ankle brachial index}

During 34 regional study workshops the GPs were specifically trained by certified specialists in vascular medicine (centres of excellence) to perform ABI measurements under standardised conditions [20], using a Doppler ultrasonic device (Kranzbühler $8 \mathrm{MHz}$, Solingen, Germany). The blood pressure cuff was used to measure systolic blood pressure in the brachial artery in both arms by use of the Doppler detector in the antecubital fossa. It was then applied to the distal calf, and the Doppler probe was used to determine systolic blood pressure at the left and right posterior and anterior tibial arteries after a 5minute rest. Measurements were performed in supine position with the upper body as flat as possible, since measurements in the sitting or semi-sitting position may result in a substantial increase in tibial artery blood pressure. Calculation of the ABI was based on the following methods (see also Table 1): the highest arterial pressure of each leg (either posterior tibial or anterior tibial artery above the ankle; method \#1), the lowest pressure (either posterior tibial or anterior tibial artery above the ankle; \#2), only the systolic pressure of the tibial anterior artery (\#3), and only the systolic pressure of the tibial posterior artery (\#4). Furthermore, the ABI was also determined after exercise, however, only in the tibial posterior artery of each leg (\#5). The ABI was calculated as follows: the ABI for each leg equals the ratio of the respective ankle pressure as determined by methods \#1-\#5 to the average of the right and left brachial artery pressures, unless there is a discrepancy of $10 \mathrm{mmHg}$ in blood pressure values between the two arms. In such a case, the higher reading was used for the ABI. For the further analyses, the higher

Table I: Description of the methods used for determination of the ankle-brachial index (ABI)

\begin{tabular}{cl}
\hline $\begin{array}{l}\text { Method of ABI } \\
\text { determination }\end{array}$ & $\begin{array}{l}\text { Procedure (nominator in the ABI } \\
\text { calculation) }\end{array}$ \\
\hline$\# 1$ & $\begin{array}{l}\text { highest systolic pressure (tibial anterior/posterior } \\
\text { artery) } \\
\text { lowest systolic pressure (tibial anterior/posterior } \\
\text { artery) } \\
\text { only systolic pressure of tibial anterior artery } \\
\text { only systolic pressure of tibial posterior artery } \\
\text { after exercise (tibial posterior artery only) }\end{array}$ \\
\hline 4 &
\end{tabular}

The blood pressure measurements were performed on each leg as described in the methods section. The denominator in all calculations was the average of the right and left brachial arterial pressure (unless discrepancy of $\geq 10 \mathrm{mmHg}$, which led to the use of the higher pressure). of the two $\mathrm{ABI}$ values obtained from the left and the right ankle was used.

\section{Determination of PAD}

An $\mathrm{ABI}<0.90$ in either leg was considered as evidence of PAD for all five determination methods. However, the classification of patients according to the ABI was modified as follows: patients with an $\mathrm{ABI}>1.5$ and no history of peripheral revascularisation and/or amputation on account of PAD were excluded from the analysis. An ABI of 1.5 or higher is consistent with poorly compressible leg arteries and is unreliable for gauging arterial perfusion accurately. Additionally, patients with a history of peripheral vascular revascularisation and/or limb amputation and $A B I$ values $\geq 0.9$ were classified as PAD patients.

\section{Statistical analysis}

For the association between PAD status (determined using the different modes of ABI calculation and using a cut off value of 0.9 ) and the presence of cardiovascular events (in the patient's history), odds ratios and sensitivities for the 'detection' of the history of cardiovascular events (with corresponding specificities) were calculated. In addition, the association between $\mathrm{ABI}$ (determined using the different modes of calculation) and prevalent cardiovascular events was described by receiver operating characteristic (ROC) curves. Statistical analyses were performed with SAS version 8.2 (SAS Institute Corp., Cary, NC, 1999).

\section{Results}

\section{Description of the sample}

A total of 27,486 patients aged 65 years or older $(10,722$ men and 16,764 women) were screened by their GP in the recruitment week of the study. Only patients with written informed consent could be included, and this was provided for this long-term study by only about one quarter of patients $(n=6880)$. The age distribution of the patients was consistent with the age distribution in Germany [23] (Table 2). Compared to the patients screened, the percentage of recruited patients aged between 65 and 74 was slightly higher, whereas that of patients aged $\geq 80$ years was somewhat lower. Thus, compared to the general population, the younger patients were over-represented in the study, whilst the older were slightly under-represented (Table 2). The gender distribution of included patients was very similar to that of the general population in Germany (not shown).

\section{Prevalence estimates of PAD}

The percentage of patients with symptomatic PAD was $9.2 \%$, which included intermittent claudication $(4.6 \%)$, and/or positive Rose questionnaire $(2.3 \%)$, and/or peripheral event $(2.3 \%)$. 
Table 2: Age distribution of screened and included patients compared with the age distribution in Germany within the respective age categories

\begin{tabular}{cccc}
\hline $\begin{array}{c}\text { Age } \\
\text { category } \\
\text { (years) }\end{array}$ & $\begin{array}{c}\text { Age } \\
\text { distribution in } \\
\text { Germany (\%) }\end{array}$ & $\begin{array}{c}\text { Patients screened } \\
\text { for getABI (\%) }\end{array}$ & $\begin{array}{c}\text { Patients included } \\
\text { in getABI (\%) }\end{array}$ \\
\hline $65-69$ & 30.1 & 30.9 & 34.6 \\
$70-74$ & 26.6 & 26.5 & 32.1 \\
$75-79$ & 21.4 & 20.0 & 21.7 \\
$80-84$ & 9.7 & 13.3 & 9.4 \\
$\geq 85$ & 12.2 & 9.3 & 2.2 \\
\hline
\end{tabular}

Source for age distribution in Germany: [23].

As shown in Fig. 1, the PAD prevalence estimate was profoundly affected by the mode of ABI calculation. While method \#1 yielded the lowest prevalence estimate $(18.0 \%)$, method \#2 resulted in a value nearly double that (34.5\%). The differences between methods \#3, \#4 and \#5 were less pronounced $(29.0 \%, 24.2 \%$ and $27.8 \%$ respectively).

\section{Association between PAD and cardiac events}

The association between PAD and cardiac events was influenced by the mode of $A B I$ determination when odds ratios (OR) were used for the description of this association. Cardiac events were classified as myocardial infarction or coronary revascularisation $(n=821$ patients). As demonstrated in Fig. 2, the univariate OR at the cut-off point of 0.9 was highest in method \#1 (2.2) and lowest in method \#2 (1.7). In methods \#3-\#5, the OR was 1.9 and did not differ between the modes of ABI calculation. The sensitivity for detection of a history of cardiac events was

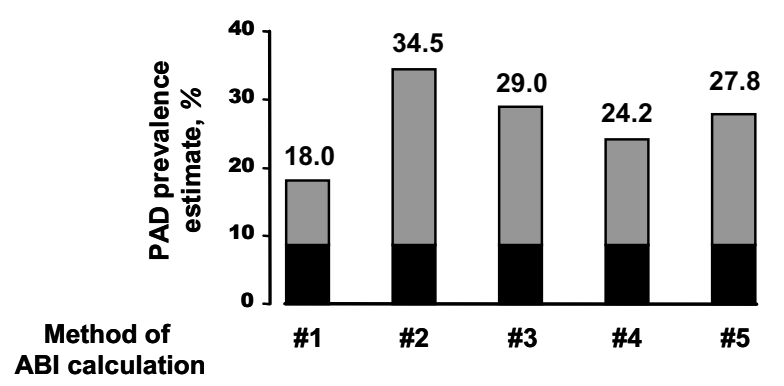

\section{Figure I}

Prevalence estimates for PAD using different methods for $A B I$ calculation. $P A D$ was defined by an $A B I$ value $<0.9$ (grey bars) or clinical evidence of PAD (black bars). Clinical evidence of PAD included positive Rose questionnaire, intermittent claudication and peripheral vascular event. highest in method \#2 (46.1\%) and lowest in method \#3 $(30.1 \%)$. In contrast, the specificity was highest in method \#1 (83.6\%) and lowest in method \#2 (67.1\%). In methods \#3-\#5, the respective sensitivities and specificities were in the same range and did not differ appreciably between the ABI calculation methods.

However, using receiver operating characteristic (ROC) methodology, the association between PAD according to the different modes of ABI calculation and cardiac events was nearly the same, with only slight differences between the respective ROC curves (Fig. 3 ).

\section{Discussion}

Determination of $\mathrm{ABI}$ allows the non-invasive and reliable detection and quantification of PAD. It is one of the most widely used methods in the epidemiology of PAD since it can be easily performed in large-scale studies, with low variability of measurements between different observers $[12,17,24]$. At the same time, it is increasingly used as screening measure in primary care. However, different modes of ABI calculation are used in the literature. In some reports, the highest arterial pressure in each leg is used, whilst in others the lowest arterial pressure serves to determine the ABI. Alternatively, only the tibialis posterior or dorsalis pedis pressure is used, or the pressures of one leg are averaged [18,24-27]. However, the optimal method for $\mathrm{ABI}$ calculation for estimating the prevalence of PAD and predicting mortality and other outcomes in PAD has to our knowledge not been determined.

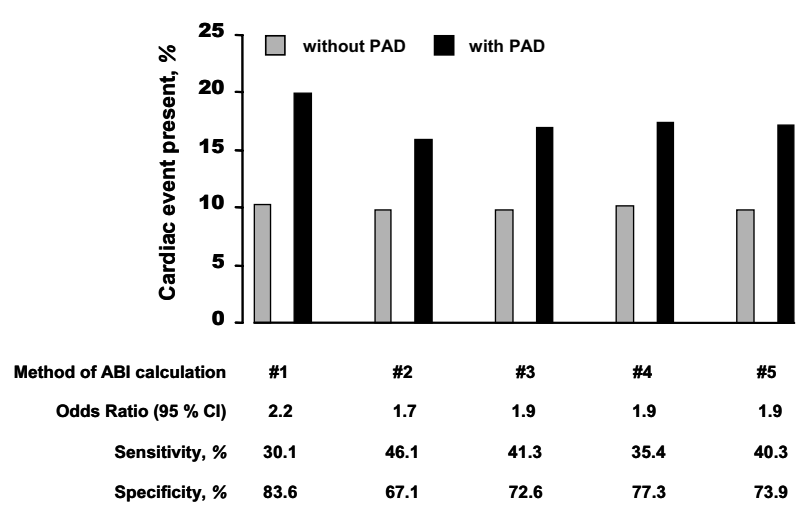

Figure 2

Association between PAD and history of cardiac event using odds ratios (OR). PAD was defined by an $A B I$ value $<0.9$ or clinical evidence of PAD, while history of cardiac event was evident after myocardial infarction or coronary revascularisation. OR, sensitivity and specificity are shown for the different modes of $A B I$ calculation. Sensitivity and specificity are given for the 'detection' or 'exclusion', resp., of a history of cardiac events. 


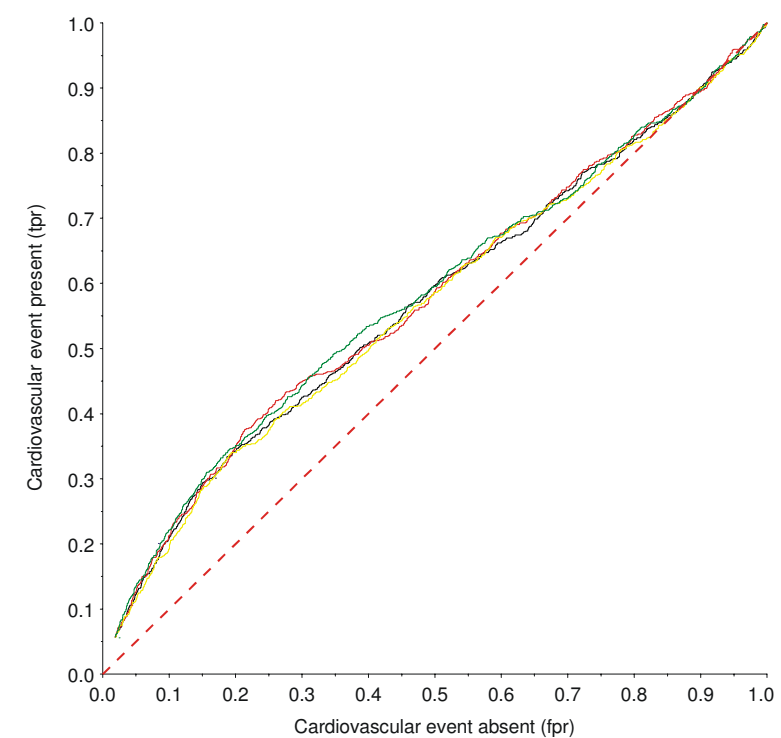

Figure 3

ROC curves for the association between $A B I$ values (according to different methods for $A B I$ calculation) and the history of cardiovascular events (myocardial infarction or coronary revascularisation). Black line, method \#I; red line, method \#2; yellow line, method \#3; green line, method \#4. The red dashed line represents the line of identity of tpr and fpr.

This is the first large-scale epidemiological study to screen an unselected sample of patients in primary care for the prevalence of PAD using different methods for the calculation of the ABI. The data confirm the high prevalence of PAD in primary care $[28,29]$, indicating that - at least about every fifth subject aged $\geq 65$ years, is a PAD patient.

In our study, and as recommended by the American Heart Association [30], taking the higher of the two systolic pressures (method \#1, tibial posterior and anterior artery) resulted in the most conservative estimate of the prevalence of PAD. However, at ABI values > 1.5, the presence of poorly compressible ankle arteries due to calcified vessels should be taken into account. Incompressible arteries are frequently observed in diabetics and haemodialysis patients and may result in incorrectly high $\mathrm{ABI}$ values [31].

Modes of ABI calculations in which the dorsalis pedis (which is the distal extension of the anterior tibial artery) pressure (method \#3) serves as the numerator may be misleading and not generally suitable in primary care, since an absent dorsalis pedis signal due to hypoplasia is described in $8-12 \%$ of healthy subjects without PAD $[11,32]$. The smaller diameter of the dorsalis pedis artery relative to the posterior tibial artery may be more difficult for general physicians to locate with the Doppler probe (leading to an underestimate of the true pressure), and in addition, artery pressures due to pulse wave reflection in smaller vessels may be different in the two vessels. [14]

Thus, if the numerator were defined by the dorsalis pedis pressure (method \#3) or the lowest ankle pressure (method \#2) (which would be 0 if the dorsalis pedis pressure is not detectable), the value 0 would be attributed to these legs although PAD would be absent. Likewise, in a smaller study in healthy subjects, Aboyans et al. [26] disqualified methods involving the lower arterial pressure at the ankle, since this method cannot distinguish between hypoplastic or obstructed arteries. As in our approach, that study also recommended the use of the higher arterial pressure at the ankle for calculation of the ABI, which yielded a PAD prevalence estimate of about $5 \%$ at the cutoff point of 0.9. This lower value can be explained by the fact that patients with history of PAD were excluded in the study by Aboyans et al. Moreover, the cohort was significantly younger, with only $26 \%$ of the patients being $>65$ years [26].

In another approach, McDermott et al. correlated three modes of ABI determination to leg functioning parameters in PAD patients [33]. As in the present observations, using the lower of the two arterial pressures at the ankle (method \#2) resulted in a significantly higher PAD prevalence. However, their results suggested that the ABI, determined by averaging the dorsalis pedis and posterior tibial arterial pressures in each leg, may be most predictive of walking endurance and walking speed in patients with peripheral arterial disease. In contrast to that study, which was performed with regard to leg functioning parameters on selected patients with high prevalence of PAD, the present investigation was performed on a large-scale general population aged 65 years or older. Consequently, the results may not be directly comparable.

Another finding is of considerable importance for the practical use of the ABI for screening purposes. While the different modes of ABI calculation profoundly affected the estimation of PAD prevalence, there was no major effect on the association between other concomitant manifestations of atherothrombotic disease, i.e. cardiovascular events. ROC analyses were performed to describe the relationship between sensitivity and specificity of different $\mathrm{ABI}$ values (according to different modes of calculation) with respect to history of cardiovascular events. Interestingly, the respective ROC curves differed only marginally between the diverse modes of calculation, indicating that the strength of association between the ABI and cardiovascular events is largely independent of the mode of $\mathrm{ABI}$ determination. Thus, an abnormal $\mathrm{ABI}$, irrespective of the mode of calculation, is associated with the same preva- 
lence of cardiovascular events at a "mode-specific" cut-off point.

For the assessment of exercise ABI, in contrast to a previous methodological study [14] that used the posterior tibial artery or the dorsalis pedis artery (which is the distal extension of the anterior tibial artery), due to the reasons given above $[14,32]$ we chose to focus on measurements on one vessel, the posterior tibial artery. Of note, even the determination of the $\mathrm{ABI}$ after exercise did not increase the strength of association with concurrent (or history of) cardiovascular events. Since ABI calculation after exercise is a demanding procedure in terms of time and manpower, and since there is no obvious advantage over other methods, this approach may not be suitable for routine determination of the $\mathrm{ABI}$ in general practice.

\section{Conclusion}

To summarise, for improved comparability of data in epidemiological and clinical studies employing the $\mathrm{ABI}$, one mode of ABI calculation should be universally used. As previously suggested by the American Heart Association, taking the higher of the two arterial pressures at the ankle may be the most suitable procedure for $\mathrm{ABI}$ determination in primary care.

\section{Competing interests}

MM is an employee of Sanofi-Aventis, Germany, the manufacturer of clopidogrel which is used, among others, in the indication peripheral arterial disease. The other authors declare that they have no competing interests.

\section{Authors' contributions}

$\mathrm{CD}$ and HJT are on the steering committee of the getABI study; all other authors - with the exception of SL - are on the advisory board. SL had substantial impact on the design of the getABI study. JRA, RLH, GT and MM participated in the study design and interpreted the results. $\mathrm{SL}$, $\mathrm{CD}, \mathrm{HJT}$ and DP planned or performed the statistical work required for this paper. DP and SL wrote the paper. All authors read and approved the final manuscript.

\section{Acknowledgements}

The study was supported by an unrestricted educational grant from SanofiAventis, Berlin, Germany. The authors thank the centres of excellence for their commitment. We appreciate the help of the participating GPs for collecting the data for the study and their practice staff for their assistance.

\section{References}

I. Fowkes FG, Housley E, Cawood EH, Macintyre CC, Ruckley CV, Prescott RJ: Edinburgh Artery Study: prevalence of asymptomatic and symptomatic peripheral arterial disease in the general population. Int/ Epidemiol 1991, 20(2):384-392.

2. McDermott MM, Mehta S, Greenland P: Exertional leg symptoms other than intermittent claudication are common in peripheral arterial disease. Arch Intern Med 1999, 159(4):387-392.

3. Norgren L, Hiatt WR, Dormandy JA, Nehler MR, Harris KA, Fowkes FGR: Inter-Society Consensus for the Management of Periph- eral Arterial Disease (TASC II). Eur J Vasc Endovasc Surg 2007, 33(Suppl. I):SI-S75.

4. Criqui MH, Langer RD, Fronek A, Feigelson HS, Klauber MR, McCann T], Browner D: Mortality over a period of 10 years in patients with peripheral arterial disease. N Engl J Med 1992, 326(6):38I-386.

5. McKenna $M$, Wolfson $S$, Kuller $L$ : The ratio of ankle and arm arterial pressure as an independent predictor of mortality. Atherosclerosis I991, 87(2-3): I 19-128.

6. Smith GD, Shipley MJ, Rose G: Intermittent claudication, heart disease risk factors, and mortality. The Whitehall Study. Circulation 1990, 82(6): 1925-1931.

7. Leng GC, Lee AJ, Fowkes FG, Whiteman M, Dunbar J, Housley E, Ruckley CV: Incidence, natural history and cardiovascular events in symptomatic and asymptomatic peripheral arterial disease in the general population. Int J Epidemiol 1996, 25(6): $1|72-||8|$.

8. McDermott MM, Kerwin DR, Liu K, Martin GJ, O`Brian E, Kaplan H, Greenland $P$ : Prevalence and significance of unrecognized lower extremity peripheral arterial disease in general medicine practice. J Gen Intern Med 200I, 16:384-390.

9. Hirsch AT, Criqui MH, Treat-Jacobson D, Regensteiner JG, Creager MA, Olin JW, Krook SH, Hunninghake DB, Comerota AJ, Walsh ME, McDermott MM, Hiatt WR: Peripheral arterial disease detection, awareness, and treatment in primary care. J Am Med Ass 200I, 286(II): I3I7-I324.

10. Criqui MH, Coughlin SS, Fronek A: Noninvasively diagnosed peripheral arterial disease as a predictor of mortality: results from a prospective study. Circulation 1985, 72(4):768-773.

II. Criqui MH, Fronek A, Klauber MR, Barrett-Connor E, Gabriel S: The sensitivity, specifity, and predictive value of traditional clinical evaluation of peripheral arterial disease: results from noninvasive testing in a defined population. Circulation 1985, 7 I(3):5।6-522.

12. Kaiser V, Kester AD, Stoffers HE, Kitslaar PJ, Knottnerus JA: The influence of experience on the reproducibility of the anklebrachial systolic pressure ratio in peripheral arterial occlusive disease. Eur J Vasc Endovasc Surg 1999, I 8(I):25-29.

13. Yao ST, Hobbs JT, Irvine WT: Ankle systolic pressure measurements in arterial disease affecting the lower extremities. $\mathrm{Br}$ J Surg 1969, 56(9):676-679.

14. Hiatt WR, Hoag S, Hamman RF: Effect of diagnostic criteria on the prevalence of peripheral arterial disease. The San Luis Valley Diabetes Study. Circulation 1995, 9 I(5): I472- 1479.

15. Fowkes FG: The measurement of atherosclerotic peripheral arterial disease in epidemiological surveys. Int J Epidemiol 1988, I 7(2):248-254.

16. Criqui MH, Denenberg JO, Bird CE, Fronek A, Klauber MR, Langer RD: The correlation between symptoms and non-invasive test results in patients referred for peripheral arterial disease testing. Vasc Med 1996, I(I):65-7I.

17. Holland-Letz T, Endres H, Biedermann S, Mahn M, Kunert J, Groh S, Pittrow D, von Bilderling P, Sternitzky R, Diehm C: Reproducibility and reliability of the ankle brachial index as assessed by vascular experts, family physicians and nurses. Vasc Med 2007, I2(2): $105-112$.

18. Greenland P, Abrams J, Aurigemma GP, Bond MG, Clark LT, Criqui $\mathrm{MH}$, Crouse JR 3rd, Friedman L, Fuster V, Herrington DM, Kuller LH, Ridker PM, Roberts WC, Stanford W, Stone N, Swan HJ, Taubert KA, Wexler L: Prevention Conference V. Beyond secondary prevention: Identifying the high-risk patient for primary prevention. Noninvasive tests of atherosclerotic burden. Circulation 2000, $101(1)$ :E16-22.

19. Arbeitsgruppe Epidemiologische Methoden der Deutschen Arbeitsgemeinschaft Epidemiologie (DAE): Leitlinien und Empfehlungen zur Sicherung von Guter Epidemiologischer Praxis (GEP). Available. [http://www.gmds.de/publikationen/ Ib LeitlinienUndEmpfehlungen April2004.pdf].

20. getABI Study Group: getABI: German epidemiological trial on ankle brachial index for elderly patients in family practice to detect peripheral arterial disease, significant marker for high mortality. VASA 2002, 3 I (4):24I-248.

21. Diehm C, Lange S, Darius H, Pittrow D, von Stritzky B, Tepohl G, Haberl RL, Allenberg JR, Dasch B, Trampisch HJ: Association of low ankle brachial index with high mortality in primary care. Eur Heart J 2006, 27(14): 1743-1749. 
22. Rose GA: The diagnosis of ischaemic heart pain and intermittent claudication in field surveys. Bull World Health Organ 1962, 27:645-658.

23. Federal Statistical Office: Statistical Yearbook 200I for the Federal Republic of Germany. Stuttgart , Metzler-Poeschel; 200 I.

24. Fowkes FG, Housley E, Macintyre CC, Prescott RJ, Ruckley CV: Variability of ankle and brachial systolic pressures in the measurement of atherosclerotic peripheral arterial disease. J Epidemiol Community Health I988, 42(2): I 28- I 33.

25. Fisher CM, Burnett A, Makeham V, Kidd J, Glasson M, Harris JP: Variation in measurement of ankle-brachial pressure index in routine clinical practice. J Vasc Surg 1996, 24(5):87|-875.

26. Aboyans V, Lacroix P, Preux PM, Vergnenegre A, Ferrieres J, Laskar $M$ : Variability of ankle-arm index in general popu-lation according to its mode of calculation. IntAngiol 2002, 2 I(3):237-243.

27. Aboyans V, Lacroix P, Lebourdon A, Preux PM, Ferrieres J, Laskar M: The intra- and interobserver variability of ankle-arm blood pressure index according to its mode of calculation. J Clin Epidemiol 2003, 56(3):215-220.

28. Meijer WT, Hoes AW, Rutgers D, Bots ML, Hofman A, Grobbee DE: Peripheral arterial disease in the elderly: The Rotterdam Study. Arterioscler Thromb Vasc Biol 1998, I 8(2): I85-192.

29. Newman AB, Shemanski L, Manolio TA, Cushman M, Mittelmark M, Polak JF, Powe NR, Siscovick D: Ankle-Arm Index as a Predictor of Cardiovascular Disease and Mortality in the Cardiovascular Health Study. Arterioscler Thromb Vasc Biol 1999, I 9(3):538-545.

30. Hirsch AT, Haskal Z], Hertzer NR, et al.: ACC/AHA Guidelines for the Management of Patients With Peripheral Arterial Disease (Lower Extremity, Renal, Mesenteric, and Abdominal Aortic). Circulation 2006, I I 3:463-654

31. Emanuele MA, Buchanan BJ, Abraira C: Elevated leg systolic pressures and arterial calcification in diabetic occlusive vascular disease. Diabetes Care I98I, 4(2):289-292.

32. Yamada T, Gloviczki P, Bower TC, Naessens JM, Carmichael SW: Variations of the arterial anatomy of the foot. Am J Surg 1993, I66(2): I30-135

33. McDermott MM, Criqui MH, Liu K, Guralnik JM, Greenland P, Martin G], Pearce W: Lower ankle/brachial index, as calculated by averaging the dorsalis pedis and posterior tibial arterial pressures, and association with leg functioning in peripheral arterial disease. J VascSurg 2000, 32(6): | |64- I I7|.

\section{Pre-publication history}

The pre-publication history for this paper can be accessed here:

http://www.biomedcentral.com/1471-2458/7/147/pre pub
Publish with Bio Med Central and every scientist can read your work free of charge

"BioMed Central will be the most significant development for disseminating the results of biomedical research in our lifetime. "

Sir Paul Nurse, Cancer Research UK

Your research papers will be:

- available free of charge to the entire biomedical community

- peer reviewed and published immediately upon acceptance

- cited in PubMed and archived on PubMed Central

- yours - you keep the copyright
BioMedcentral 